\title{
C/B/S Mixed Structure-based Students Ideological and Political Work Management Mode Study
}

\author{
Jingcai $\mathrm{Xu}^{*}$ and Liang Chen
}

Xi'an Medical University, Xi'an 710021, Shaanxi, China

\begin{abstract}
With computer technology constantly development, calculation mode has transformed from centralized type to distributed type. Campus information system construction also constantly expands its range with computer technology development, students ideological and political work during university period no doubt is very necessary, in case that apply computer information management system to regularize it on the basis of traditional ideological and political management thinking, then it may achieve better results. The paper carries out summary and analysis of single C/S and single B/S, and gets information management system merits under the two modes, on a whole, disadvantages are quite a lot, in order to make up such drawbacks, the paper relies on student ideological and political work management information system frame, designs system on the basis of $\mathrm{C} / \mathrm{S}$ and $\mathrm{B} / \mathrm{S}$ mixed structure, by system designing process and network implementation platform characteristics, it concludes that mixed structural mode has characteristics of high transmission efficiency, high transmission safety and low information system cost that can provides theoretical reference for ideological and political work management information system designing.
\end{abstract}

Keywords: B/S mode, C/S mode, management information system, mixed structure, network platform operation.

\section{INTRODUCTION}

"Digitalized campus" is the first of Chinese educational informationization, is domestic universities important means to improve their own management levels and comprehensive competitive strength. The purposes for universities implementing and establishing digitalized campus is carrying out collection, handling, integration, storage, transmission and application with teaching, scientific research, management, technical services and other campus information. University students ideological and political work is also top priority of universities education, which can be well reflected from textbook setting, course setting and post-graduate entrance examination subjects setting, in order to improve students' ideological and political current status fundamentally, lots of schools have founded ideological and political management organization, the paper confronted object is ideological and political organization, it starts from the perspective of information management work, design $\mathrm{B} / \mathrm{S}$ and $\mathrm{C} / \mathrm{S}$ mixed structure mode-based student ideological and political management system, and provides theoretical basis for system designing, constructing and implementing [1].

For campus information management and $\mathrm{B} / \mathrm{S}$ and $\mathrm{C} / \mathrm{S}$ mixed mode information management system design research, lots of people have made efforts, just their efforts, information management technology has been driven and developed, which built foundation for all industries development. Among them, Liu Shu-Hua (2014) through combining ASP.NET with SQL Server 2005 [2], utilizing simple system to implement management on student basic information, in the hope of providing references for universities students' management and whole education reformation and education modernization system engineering construction. Chen Cheng (2014) adopted B/S framework to student information management system exploitation, development language was chosen from ASP.net [3], development platform used VS2008, database selected SQL Server2008, introduced universities student information management system demand analysis, system design, system implementation and system test, and utilized key techniques and tools. Xu Guo-Bao and others (2014) took medium and large scale bonding companies' OA management system as research object [4], designed an OA system that was convenient for applying, during sensitive and important information handling, through better safety $\mathrm{C} / \mathrm{S}$ framework, it fulfilled tasks, OA system that made $\mathrm{C} / \mathrm{S}$ framework as a supplement and regarded $\mathrm{B} / \mathrm{S}$ framework as priority, it was conveniently and effective implementing medium and large unit cell companies office automation [5].

The paper on the basis of formers' research, targeted at students' ideological and political work information management, it makes study in the hope of designing a set of $\mathrm{B} / \mathrm{S}$ and $\mathrm{C} / \mathrm{S}$ mixed structure-based student ideological and political work information management system on the basis of student ideological and political work management work management system framework studying and computer information management mixed mode study.

\section{SUMMARY OF MANAGEMENT INFORMATION SYSTEM OPERATION MODE UNDER C/S AND B/S}

Client/Server structure calls $\mathrm{C} / \mathrm{S}$ structure for short, is a popular information system structure in the $90 \mathrm{~s}$, under the 
structure, application system is divided into client and server two parts, their functions are respectively applying and handling (include implementing user interface and handling with human and machine interaction process) completed by Client, while data accessing and event handling are completed by Server, the scheme has implemented function distribution, which lets the terminal of Client to endure partial handling tasks but data concentrates on Server [6].

In query processing, it is up to Client to put forward query requests, and Server fulfills database checking tasks, and returns processing results back to Client through network, as Fig. (1) showed C/S system structure.

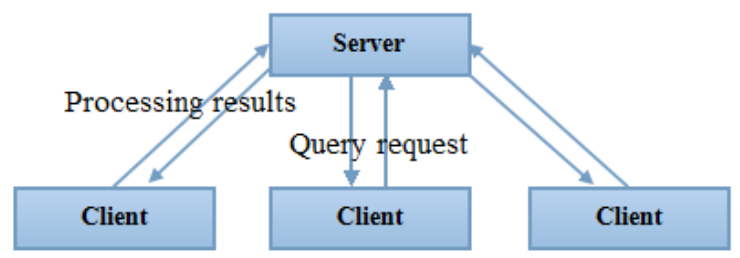

Fig. (1). C/S mode MIS.

As Fig. (1) shows, under $\mathrm{C} / \mathrm{S}$ mode, server and all clients are directly linked, data is put in the terminal of server, client puts forward requests of accessing database, it is up to server to response these requests, operating backend database, returning processing results to client-side according to requests, and server should check client access rights, and protect database as well as else, Client side tasks are responsible for human-machine exchanging, therefore, it needs to install corresponding client program, generally it is relative complicated, and increases difficulties to network management.

$\mathrm{C} / \mathrm{S}$ structure bases on the environment of LAN, it has stronger data manipulating and transaction processing ability, its requirement of data safety and fullness is higher, but Internet rapidly development, enterprise scales expanding and decentralized distribution, market competition intensified and other factors let $\mathrm{C} / \mathrm{S}$ disadvantages to be more prominent, as closure high open cost、poor compatibility, poor expansibility, difficult to maintain , has troubles in upgrading, user interface not only is disordered but also complicated in using and so on, which greatly hinders enterprise informatization pace.

$\mathrm{B} / \mathrm{S}$ model is the short form of Browser/Server mode, is further deepening $\mathrm{C} / \mathrm{S}$ model and decomposing it into an application server and a multiple database server that $\mathrm{B} / \mathrm{S}$ model is three-layer $\mathrm{C} / \mathrm{S}$ mode, its structure is as Fig. (2) shows.

$\mathrm{B} / \mathrm{S}$ mode is transforming $\mathrm{C} / \mathrm{S}$ fat client / thin server structure into thin client/ fat server, it greatly relieves client burdens, client software is simplified and only need to install unified browser software, is simple and feasible, is greatly easy network managing, due to it bases on TCP/IP protocol and HTTP protocol, it well solves cross-platform, let different models and operating system to be mutual compatible, developed MIS under B/S structure maximum features are openness and universality, is not only easier to maintain, with low development cost, greatly reducing training cost, but also protecting enterprise original investment and of more expansibility. Though B/S mode MIS has above advantages, similarly it also has certain problems, as following shows:

Due to HTTP protocol is on the basis of TCP/IP protocol, HTTP protocol's fixed format is HTML file form, the file transmission quantity is larger that will affect data transmission efficiency.

In the view of management, though program code maintenance and data backup can be done in the server, client data request and feedback information every time could only link to data server through network, it increases requests of network wide band.

After all, HTML is a kind of file form, hard to encrypt, and easy to steal and intercept as well as capture, which causes information system safety to be hard to ensure.

\section{STUDENT IDEOLOGICAL AND POLITICAL WORK MANAGEMENT SYSTEM FRAMEWORK}

University students political view points, ideological consciousness, and morality formation suffers multiplechannel, and various links influences, their education and guiding work gets involved in all departments of schools. Universities student ideological and political work management system includes student ideological political work management institution setting, management right classified organization system and leading system. In order to carry out systematic management on student ideological and political work, the paper firstly analyzes student ideological and political work management system framework, in the hope of building basis for information management system designing. Universities student

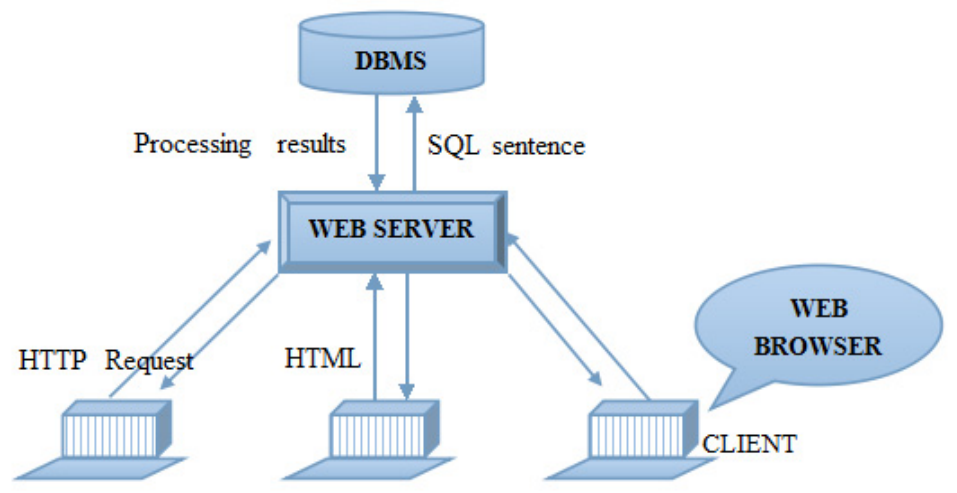

Fig. (2). B/S mode MIS. 
Table 1. Student ideological and political work management system framework contents table.

\begin{tabular}{|c|c|c|c|c|c|c|c|c|}
\hline $\begin{array}{c}\text { Core of } \\
\text { Framework }\end{array}$ & $\begin{array}{l}\text { Branch } \\
\text { Symbol }\end{array}$ & $\begin{array}{l}\text { Branch } \\
\text { Content }\end{array}$ & $\begin{array}{c}\text { Core of } \\
\text { Framework }\end{array}$ & $\begin{array}{l}\text { Branch } \\
\text { Symbol }\end{array}$ & $\begin{array}{l}\text { Branch } \\
\text { Content }\end{array}$ & $\begin{array}{c}\text { Core of } \\
\text { Framework }\end{array}$ & $\begin{array}{l}\text { Branch } \\
\text { Symbol }\end{array}$ & $\begin{array}{l}\text { Branch } \\
\text { Content }\end{array}$ \\
\hline \multirow{5}{*}{$\begin{array}{c}\text { A. } \\
\text { affiliation }\end{array}$} & A1 & Political work & \multirow{5}{*}{$\begin{array}{l}\text { B. } \\
\text { function divi- } \\
\text { sion }\end{array}$} & B1 & Organization & \multirow{5}{*}{$\begin{array}{c}\text { C. } \\
\text { operating } \\
\text { mechanism }\end{array}$} & $\mathrm{C} 1$ & $\begin{array}{c}\text { Student affairs } \\
\text { office }\end{array}$ \\
\hline & $\mathrm{A} 2$ & $\begin{array}{l}\text { Moral educa- } \\
\text { tion }\end{array}$ & & $\mathrm{B} 2$ & Supervising & & $\mathrm{C} 2$ & $\begin{array}{l}\text { Department of } \\
\text { student affairs }\end{array}$ \\
\hline & A3 & Teaching plan & & B3 & Supporting & & $\mathrm{C} 3$ & School party \\
\hline & A4 & Student affairs & & B4 & Launching & & \multirow[b]{2}{*}{$\mathrm{C} 4$} & \multirow{2}{*}{$\begin{array}{l}\text { Student work } \\
\text { committee }\end{array}$} \\
\hline & A5 & $\begin{array}{l}\text { Student work } \\
\text { system }\end{array}$ & & B5 & Leading & & & \\
\hline
\end{tabular}

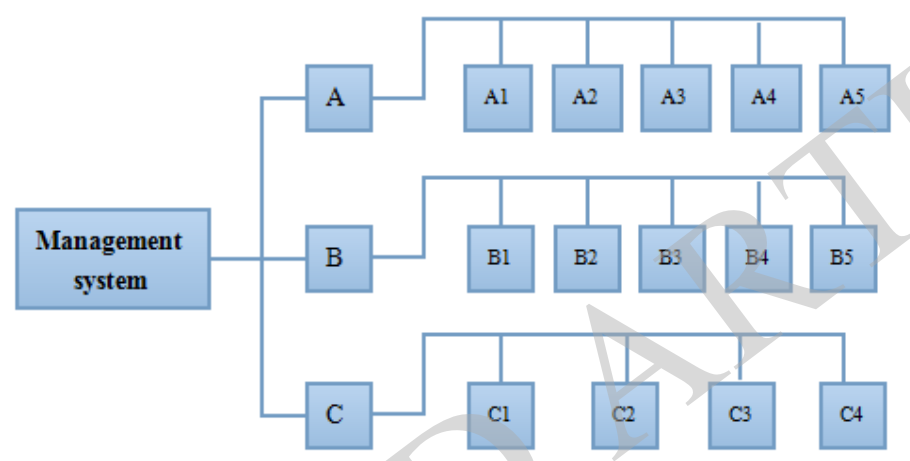

Fig. (3). Student ideological and political work management system framework structure schematic diagram.

ideological and political work management system framework divides into A. affiliation, B. function division and $\mathrm{C}$. operating mechanism, in the following it analyzes above three key links.

As Table 1 shows grade links under student ideological and political work management system framework structure.

By Table 1, it can get as Fig. (3) showed student ideological and political work management system framework structure.

As Fig. (3) shows student ideological and political work management system framework structure, in the figure the given function division divides into five branches, actual purpose of classification is to take information management system establishment convenience into consideration. In fact, universities student ideological and political work community is not loosing and mechanical combination but an organic unity, is a resultant force polymer that formed by organic cohesion of party, politics, work, league, learning and other aspects strength.

To smoothly start universities student ideological and political work, it should keep the channel open, speed moderate and state steady, so that it must establish corresponding operating mechanism, which is also operating mechanism classification in Fig. (3), classification in figure is departments that constantly optimized and founded according to time evolution, in order to coordinate administrative management and ideological education two aspects work, some schools set up department of student affairs on the basis of student affairs office, its function is leading and coordinating student ideological and political work, on this basis, lots of universities also set up school party and student work committee under the leading of school administration, in the first grade of department, general party branch deputy secretary takes in charge of leading in student work, who goes together with deputy dean, youth league general branch secretary to form into student work leading group guides and coordinates whole department student work.

\section{C/S AND B/S MIXED STRUCTURE-BASED STU- DENT IDEOLOGICAL AND POLITICAL WORK MANAGEMENT INFORMATION SYSTEM DESIGN- ING}

\subsection{Designing Thought}

Information resource is most basic and also most lively element in digitalized campus structure system, universities give prominence to the key points management information, document information content and online teaching information three aspects contents in digitalized information resources construction, management information mainly refers to information resources that are established, applied and involved in office automation (OA) and management information system (MIS).

The paper designed system mainly confront to student ideological and political work management information, therefore the system mainly adopts $\mathrm{B} / \mathrm{S}$ structure to 


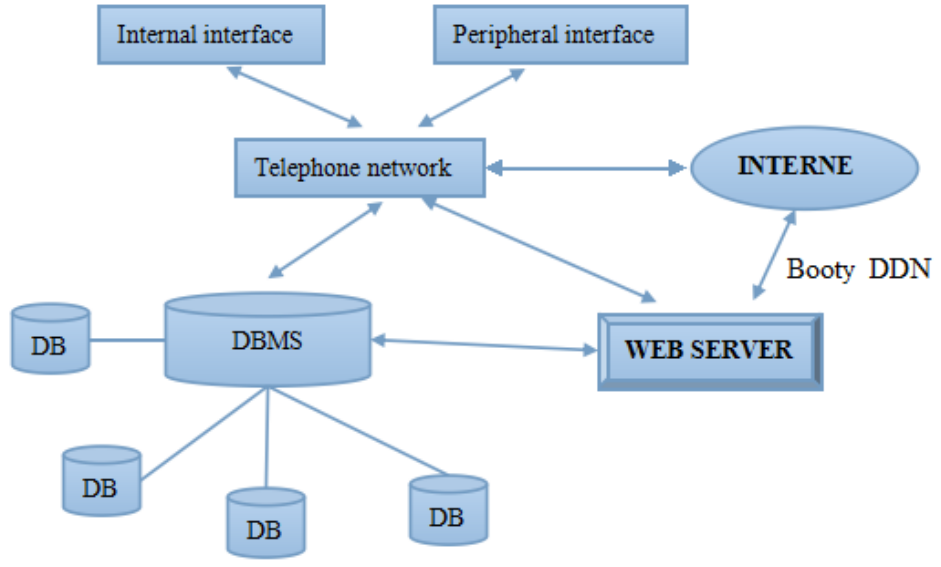

Fig. (4). Mixed structure system operating mode schematic diagram.

implement all kinds consulting and partial data collecting, reporting, as students learning status, life status and ideological status and so on. The paper schemes' designing and implementing mainly adopt Microsoft Interdev、VB Script and Frontpage as well as other development tools, take Microsoft Internet Information Server5.0 as WEB Server, and utilize its ActiveX Data Object(ADO)technology to implement WEB page and database dynamic interaction.

For complicated processing part, the paper adopts $\mathrm{C} / \mathrm{S}$ structure, the part application is fewer, but it plays important roles in whole system, which mainly targets at student ideological and political work organization dispatching, in the scheme, it adopts Delphi、 Power Puider and VB to develop.

$\mathrm{C} / \mathrm{S}$ and $\mathrm{B} / \mathrm{S}$ mixed structure-based system operating mode is as Fig. (4) shows.

As Fig. (4) shows, mixed structural operating mode integrate $\mathrm{C} / \mathrm{S}$ and $\mathrm{B} / \mathrm{S}$, it not only gives $\mathrm{C} / \mathrm{S}$ high transaction

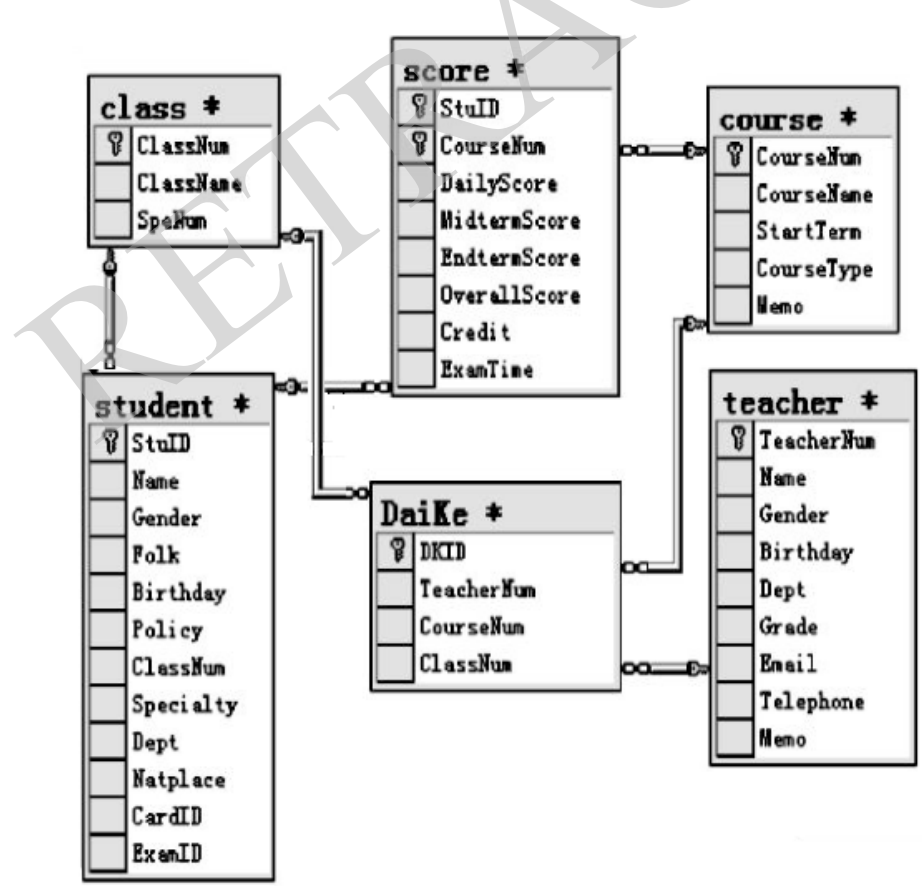

Fig. (5). Data table relationship figure. processing ability into play, but also makes full use of $\mathrm{B} / \mathrm{S}$ mode network easy expansibility and distributed features, the integration of the two has more advantages and development prospects.

\subsection{Student Information Management System Database Designing}

According to system demand, design data table to every block, in the implementation process, it fulfills data table entity fullness function through primary key constraint, ensure data not to be repeated, for the system every table data, it implements data tables reference fullness through major key and exterior key exercises, besides, during data table creating process, it should also constrain table involved field's value ranges and column validity, as constraining field length type and adding data legality and so on, during database creation process, it reflects data referred features, it can reduce database repetitive rate, the paper designed student information management system relations are as Fig. (5) shows.

\subsection{Student Ideological and Political Work Management Information System Designing}

Integrated system development process: Request analysis stage--> System overall designing stage--> Database designing and modeling stage--> System detailed design stage--> System test stage--> System maintain stage.

For student ideological and political work management information system designing overall thought, it uses SQL SERVER as database backstage, complicated service logic is implementing in SQL SERVER backstage database compilation and storage process, the layer is data layer, intermediate layer includes programming software and middleware service program, standard service and storage process description as well as others are maintained in programming software, client applies routine call middleware to handle with services, the layer is presentation layer, the whole system technical framework is as Fig. (6) shows.

In Fig. (6), presentation layer is the top layer, its main function is implementing users exchanging and data presentation to collect data for future processing, request 


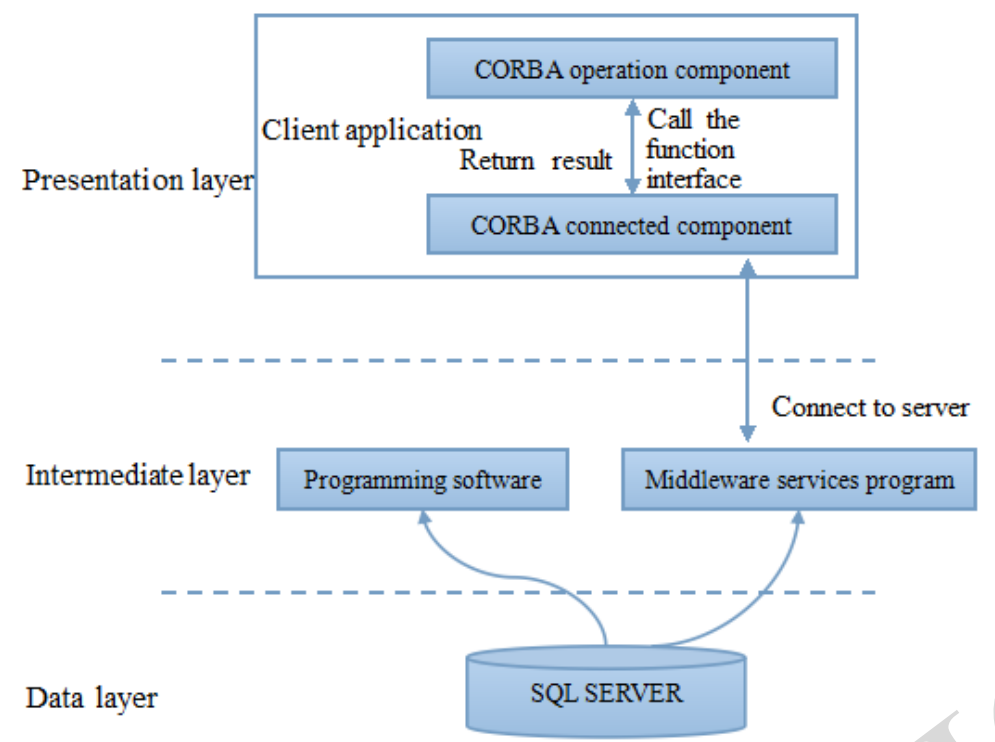

Fig. (6). Technical framework structure schematic diagram.

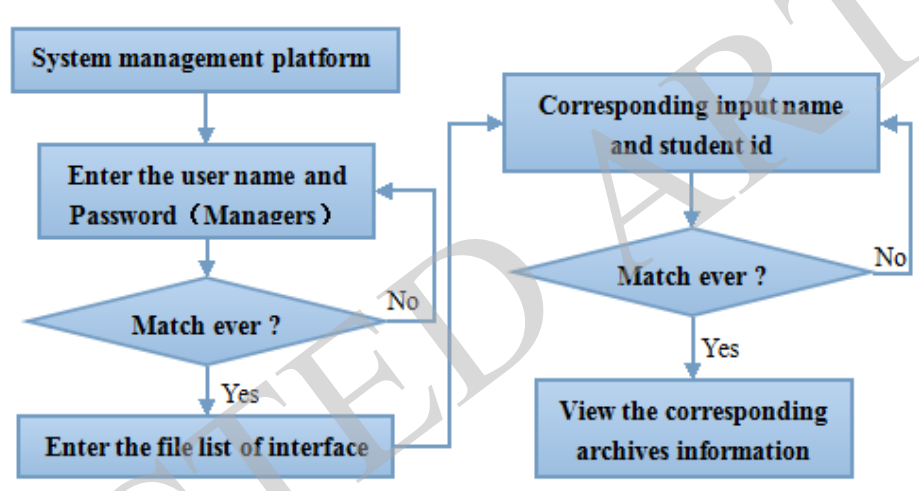

Fig. (7). Management platform utilization flow chart.

second layer service logic to call core service to process and display processing results; service logic is the intermediate layer, these modules are managed by middleware, it implements core service logic services, manages and accepts client service requests, submit data operation to resource manager and return processing result to requestor ;resource manager composes into the third layer of model, its mainly is responsible for managing application system data resources, fulfilling data operation, during server inter-block service completion process, it stores own management data through resource manager, or requests resource manager data services.

\subsection{System Network Platform Implementation}

The system adopts CORBA technology to construct three-layer system structure, in order to centralized and unified manage as well as implement three-layer distributed network system, it establishes specialized central apparatus room to put database server and WEB server, according to educational informationization requirements, the whole school internal local area network adopts $1000 \mathrm{M}$ fast Ethernet, according to intelligent building designing standard, it adopts comprehensive structure cabling technology to implement structure cabling, school internal all rooms working staff can rapidly start its own business through high speed computer network, teachers and students can also relative easily and fast login in Internet through computer in the school.

System platform classification can be divided into management platform and student application platform, from which management platform offers to student administrative staff, and student application platform offers to student perfect personal information and add moral education experiences.

As Fig. (7) management platform flow, definition of flow chart is logging in through system management platform interface, inputting user name and password, if input correctly, then it will enter into student ideological and political record list interface, otherwise, it cannot log in, after succeeding in log in, in student ideological and political record list interface, enter into student ideological and political record viewing interface on the premise knowing that every student's student number matches to his name, if students name and his number inputting are not matching, then he cannot view.

As Fig. (8) shows student application platform utilization flow, in the figure, it shows the definition is that student $\operatorname{logs}$ 


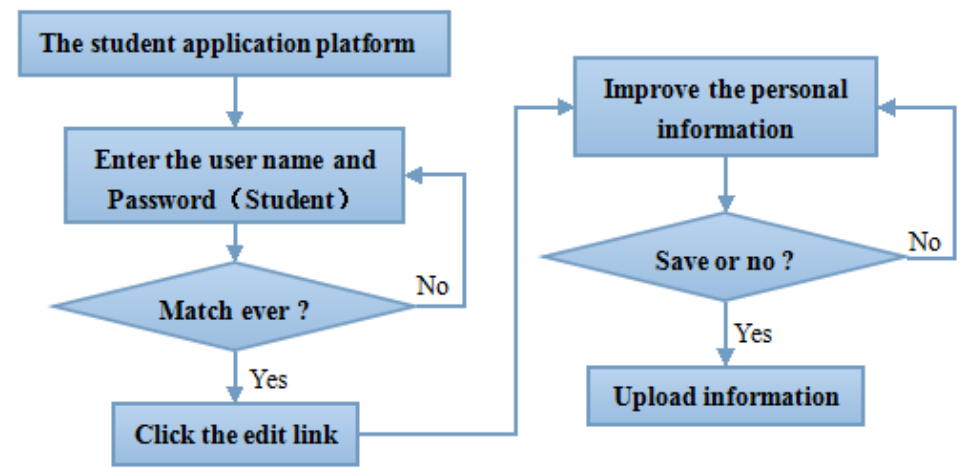

Fig. (8). Student application platform utilization flow chart.

in his own ideological and political record interface through student application platform interface, firstly it should input user name and password, if input correctly then he can enter in, otherwise not, student application platform functions not only have viewing functions, but also have revising and perfecting functions that when students click edit link, he can perfect information and revise information, after fulfill filling, save them and then can upload to management platform.

Whole system user configuration principle :it needs to adapt to multiple disciplines multiple departments' students detailed classification, fit for business flow tedious and changeable demands, all students can own accounts in $\mathrm{B} / \mathrm{S}$ system, while $\mathrm{C} / \mathrm{S}$ system is only for their own special information handling staff and school leaders and others.

Generally speaking, B/S system confronted users are more, and users' grade classification is careful, in order to protect students' confidential information and normalize all kinds of works transferring, it should treat differently with different users created contents, which is setting up different authorities for different users. Besides, it should also think about every user's authority changeability, which requires system not only has enough grades in authority distribution, but also can timely change or increase authority for users.

$\mathrm{C} / \mathrm{S}$ system mainly targets at high-rise and special data processing staff, confronted users are relative fewer, corresponding user management is also more convenient, high-rise leader users can carry out some operation that involve in security or being relative sensitive, data processing staff greatly reads data and makes data analysis.

The paper designed $\mathrm{B} / \mathrm{Sand} \mathrm{C} / \mathrm{S}$ modes have characteristics as following:

Mixed mode not only gives $\mathrm{C} / \mathrm{S}$ mode high transaction processing ability into play, but also makes full use of $\mathrm{B} / \mathrm{S}$ mode easy expansibility and distributed features; the integration of the two has larger advantages and development prospects.

High transmission efficiency:Due to school contents implement client and server directly communication without going through WEB server, so that it reduces bottleneck constraint of transmission quantity, increases data transmission quantity, school contents communication doesn't adopt HTTP protocol and HTML file form, while directly bases on more basic TCP/IP protocol, ideological and political information management system customizes transmission format according to practical situation, it avoids redundant HTML format description, and then increases data transmission speed and efficiency.

High transmission security :In the model student ideological and political information management system content communication directly bases on TCP/IP protocol, information system customizes transmission format according to practical situations, due to it uses non-text form to transmit data, through transmission data encrypting and decoding operation in transmission sender and receiver, it greatly increases data transmission security, increases system anti-attacking and system safety and stability.

Low information system cost, due to transmission efficiency improves, network wide band requirements reduce, and then system development cost reduces.

\section{CONCLUSION}

The paper bases on summary of management information system operating mode under $\mathrm{C} / \mathrm{S}$ and management information system operating mode under $\mathrm{B} / \mathrm{S}$, respectively gets $\mathrm{C} / \mathrm{S}$ and $\mathrm{B} / \mathrm{S}$ models advantages and disadvantages, in the hope of providing references for two models mixed application. Then, it states student ideological and political work management system framework, which builds foundation for $\mathrm{C} / \mathrm{S}$ and $\mathrm{B} / \mathrm{S}$ mixed structure-mixed student ideological and political work management information system designing. Finally, on the basis of overall designing thought determination, it provides student information management system database designing, student ideological and political work management information system designing and system network platform implementation plan, at last summarizes mixed structure model advantages, which provides theoretical basis for the model popularization.

\section{CONFLICT OF INTEREST}

The authors confirm that this article content has no conflict of interest.

\section{ACKNOWLEDGEMENTS}

Declared none. 


\section{REFERENCES}

[1] C. Chen, "Student information management system designing and implementation," China Management Informationization, vol. 17, no. 7, pp. 42-43, 2014.

[2] S-H. Liu, "Student information management system designing and implementation," Information Communication, vol. 33, no. 5, pp. 110-111, 2014.

[3] L-J. Ni, "B/S structure and C/S structure-based mixed system structural study," Fujian Computer, vol. 12, no. 9, pp. 124-125, 2010.
[4] W-P. Song, "OA system right control designing and implementation under B/S mode," Computer Engineering and Application, vol. 55, no. 35, pp. 199-201, 2004

[5] J-X. Xia, "Internet and management information system," Сотрuter Engineering and Application, vol. 36, no. 3, pp. 142-144, 2000.

[6] B-G. Xu, "B/S and C/S structural collaboration information management system research and application," Application Exchange, vol. 120 , no. 270 , pp. 49-50, 2014.

Received: June 10, 2015

(C) Xu and Chen; Licensee Bentham Open.

This is an open access article licensed under the terms of the (https://creativecommons.org/licenses/by/4.0/legalcode), which permits unrestricted, noncommercial use, distribution and reproduction in any medium, provided the work is properly cited. 